\title{
Jean Itard e Victor do Aveyron: olhares contemporâneos sobre a narrativa de uma experiência pedagógica do início do século XIX
}

Tania Mara Zancanaro Pieczkowski*

\section{Resumo}

Este artigo surgiu do desafio do Grupo de Estudos e Pesquisa em Educação Especial e Inclusão - GEPE da Universidade Federal de Santa Maria (UFSM), para escrever sobre o encontro do médico Jean Itard e o garoto selvagem conhecido como Victor do Aveyron. A elaboração deste texto toma como materialidades empíricas as meticulosas narrativas escritas por Itard na França, no período de 1801 a 1806. O estudo objetiva analisar esse acontecimento histórico a partir das leituras do presente e compreender a influência de epistemologias e políticas educacionais nas práticas da Educação Especial. O estudo evidencia as mudanças entre uma educação individual, pautada da educação dos sentidos e políticas atuais de inclusão, instigando, também, a refletir se a lógica da "educação para todos" não apresenta o risco da negação da diferença. A análise dos relatórios do trabalho educacional de Itard e Victor do Aveyron contribui para a compreensão de uma época, mas provoca também a reflexão acerca de indagaçôes ainda presentes quanto à interferência de aspectos biológicos e sociais no desenvolvimento humano. Apesar dos entusiasmos e desencantos explicitados por Itard na educação de Victor, sua experiência analisada com referenciais epistemológicos contemporâneos contribui para a compreensão da necessária ruptura com crenças no determinismo biológico, enfatizando a importância da interação social para a aprendizagem e desenvolvimento humano.

Palavras-chave: Educação especial; Interação social; Isolamento social.

* Professora doutora da Universidade Comunitária da Região de Chapecó, Chapecó, Santa Catarina, Brasil. 


\section{Jean Itard and Victor of Aveyron: contemporary perspectives on the narrative of a teaching experience in the early 19th century}

\section{Abstract}

This article arose from the challenge of the Special Education and Inclusion Study and Research Group - GEPE at the Federal University of Santa Maria (UFSM), to write about the meeting between the physician Jean Itard, and the wild boy known as Victor do Aveyron. The preparation of this text takes the meticulous narratives written by Itard in France, from 1801 to 1806, as empirical materiality. The study aims to analyze this historical event from the present readings and understand the influence of epistemology and educational policies in Special Education practices. The study shows the changes between an individual education, guided by the education of the senses and current inclusion policies, and also makes an encouragement to reflect if the logic of "education for all" does not present the risk of denial of difference. The Analysis of the reports of Itard and Victor do Aveyron' educational work contributes to the understanding of an era, and it also provokes reflection about the still present inquiries into the interference of biological and social aspects in human development. Despite the enthusiasms and disappointments explained by Itard in Victor's education, his analyzed experience with contemporary epistemological frameworks contributes to the understanding of the necessary break with belief in biological determinism, emphasizing the importance of social interaction for learning and human development.

Keywords: Special Education; Social interaction; Social isolation.

\section{Introdução}

Este artigo representa o desafio de olhar para um acontecimento de mais de duzentos anos a partir do contemporâneo. O elemento que nos une são os clássicos relatórios do médico Jean Itard (1774-1838), escritos no período de 1801 a 1806, sobre a educação de um menino selvagem, denominado Victor do Aveyron. Os relatórios escritos por Itard, materialidades empíricas para a análise apresentada neste texto, narram a sua experiência científica e pedagógica com Victor do Aveyron, encontrado (capturado) em janeiro de 1800, aparentando ter aproximadamente 12 anos, nas florestas de La Caune, no sul da França. O nome Victor foi atribuído pelo interesse que o menino manifestava pelo som "o". Com hábitos selvagens, aparentando ser mudo e surdo, pois se comunicava por grunhidos, o menino despertou o interesse de filósofos, cientistas e da sociedade em geral, pois representava "uma promissora oportunidade de confirmar seja a teoria do 'bom selvagem' de Rousseau, seja a da 'estátua' de Condillac e, por ela, a da 'tábula rasa' de Locke” (PESSOTI, 1084, p. 36).

O menino selvagem alimentava-se de nozes, castanhas, raízes e resistia ao contato humano, embora algumas vezes tenha sido visto por moradores da região antes de sua captura. Consta na literatura que Victor foi levado a Paris em agosto de 1800 
e encaminhado ao Instituto Nacional de Surdos-Mudos, criado pelo Abbé-de L'Epee, onde permaneceu por uma década.

O primeiro relatório escrito por Itard é denominado Da educaçấo de um homem selvagem ou dos primeiros desenvolvimentos fisicos e morais do jovem Selvagem do Aveyron, e foi registrado após nove meses de trabalho. Esse relatório foi apresentado por Itard à Societé des Observateurs de l" Homme em outubro de 1801.

O segundo registro de Itard, intitulado Relatório feito a Sua Excelência o Ministro do Interior sobre os novos desenvolvimentos e o estado atual do Selvagem do Aveyron, é apresentado em setembro de 1806, atendendo solicitação do Ministro do Interior, que ameaçava interromper o custeio ao trabalho em andamento.

Abracei a ideia da escrita, animada pelas leituras do livro "A educação de um selvagem: as experiências pedagógicas de Jean Itard”, organizado por Banks-Leite e Galvão (2000), no qual estão publicados os relatórios de Itard, os quais já foram tema de aulas que coordenei como professora das disciplinas de Psicologia da Educação e Fundamentos da Educação Especial em cursos de Licenciaturas. O meu entusiasmo deve-se, também, às minhas vivências como professora de educação especial, atuando, no início da profissão, em uma Associação de Pais e Amigos dos Excepcionais ${ }^{1}$ - APAE, e cujo trabalho inicial, na década de 1980 , fortemente pautado na educação dos sentidos, na teoria empirista-sensualista de Condillac (1715 - 1780), aproxima-se do que Itard apresenta. Assim, surgiram os questionamentos: a) O que mudou na educaçáo especial desde a experiência relatada por Itard?, e b) Quem são e como são formados os profissionais que atuam na educação especial?

Segundo Pessoti (1984), Jean Marc Gaspard Itard foi educado em colégios religiosos. Trabalhou no hospital militar de Soliers e, mesmo sem conhecimentos da medicina, encantou-se pelo trabalho médico. Após brilhantes estudos, assume, aos 25 anos, o cargo de médico-chefe do Instituto Imperial dos Surdos-Mudos². Devido ao seu prestígio profissional, o ministro do interior da França, Champagny, confia-lhe a tarefa de educar o menino selvagem de Aveyron. As ideias de Itard, derivadas do Essay de Locke e da teoria da estátua de Condillac, despertam seu interesse para as relaçóes entre "fonação e audição, linguagem e pensamento, percepção e abstração, cultura e inteligência, experiência e criação" (PESSOTI, 1984, p. 30). Segundo o autor, Itard foi o primeiro pedagogo da oligofrenia e teórico da educação especial de deficientes mentais.

\section{Educação e diferença: uma prática ainda complexa}

Os relatórios escritos por Itard mostram-se contemporâneos, numa perspectiva microgenética de pesquisa. Os escritos revelam Itard predominantemente na posição de cientista, de pesquisador, relacionando-se com Victor como sujeito-objeto, embora também apresente narrativas de uma relaçáo educador-educando. $\mathrm{O}$ texto explicita os diferentes papéis ocupados pelo cientista e o educador,

[...] e clara a impossibilidade de, adotada a atitude do primeiro, com o distanciamento e a coisificaçáo que, no limite, ela supóe, 
realizar a tarefa do segundo. A ciência possível para o educador é o registro e a reflexão sobre sua ação, que só pode ser a efetivação de uma relação de sujeito para sujeito. (GALVÃO; DANTAS, 2000, p. 101).

No relatório I, Itard descreve com detalhes os primeiros comportamentos de Victor e as tentativas de aproximação e educação. Além do relato da captura de Victor, atribui ao isolamento social a causa do mutismo e hábitos estranhos, revelando a expectativa de que o menino "seria passível de reeducação, desde que submetido a métodos adequados" (BANKS-LEITE; GALVÃO, 2000, p. 17). Segundo as autoras, nesse período, Itard torna-se famoso e recebe honrarias em razáo desse trabalho.

No segundo relatório, Itard deixa transparecer seu envolvimento com o trabalho de educar Victor, suas conquistas e também seus desencantos e frustraçóes, o que transparece em sua afirmação:

Falar-lhe do selvagem do Aveyron é reproduzir um nome que hoje já não inspira nenhuma espécie de interesse; é lembrar um ser esquecido por aqueles que se limitaram a vê-lo, e desdenhado por aqueles que acreditaram julgá-lo. (ITARD, 2000, p. 183).

Os registros nos remetem à complexidade da educaçáo especial. Revela metodologias difundidas da época, pautadas na educação dos sentidos. Ao longo dos trabalhos, Itard revela incerteza se Victor tem seus comportamentos e respostas, principalmente as intelectuais, moldadas por aspectos ambientais, devido ao abandono desde a infância à vida na floresta e, dessa forma, ao isolamento social ou, por aspectos orgânicos. Apesar do tensionamento acerca da influência de aspectos biológicos e sociais, o isolamento de Victor prosseguiu na civilização. Não há relatos, por exemplo, de Victor interagindo com pessoas de sua idade durante o período em que Itard empreendeu esforços para educá-lo, mas de convivência social restrita a poucas pessoas.

A complexidade da avaliação de estudantes com deficiência é expressa por Itard no preâmbulo da carta enviada ao Ministro do Interior da França:

Para expressar o estado atual do Selvagem do Aveyron, seria necessário lembrar seu estado passado. Esse rapaz, para ser julgado sadiamente, só deve ser comparado a si mesmo. Aproximado a um adolescente da mesma idade, não é mais que um ser desgracioso, rebotalho da natureza, como o foi da sociedade. Mas, se nos atemos aos dois termos de comparação oferecidos pelo estado passado e o estado presente do jovem Victor, ficamos surpreendidos com o espaço imenso que os separa; e podemos indagar se Victor não difere mais do Selvagem do Aveyron, em sua chegada a Paris, do que difere dos outros indivíduos de sua idade e de sua espécie. (ITARD, 2000, p. 184).

Essa passagem do relatório de Itard, somada a pesquisas atuais ajudam a compreender a inquietação vivida por docentes que deparam com a fronteira entre "acolher" o estudante com deficiência "incluído" nas turmas e a pressão para atender às expectativas padronizadas de formação dos estudantes em cada etapa. Como Victor seria avaliado no cenário brasileiro atual? Estaria incluído em uma escola regular? Par- 
ticiparia da Avaliação da Alfabetização Infantil - Provinha Brasil, que visa investigar o desenvolvimento das habilidades relativas à alfabetização e ao letramento em Língua Portuguesa e Matemática, desenvolvidas pelas crianças matriculadas no $2^{\circ}$ ano do ensino fundamental das escolas públicas brasileiras? Ou, em razão de sua idade, participaria da Avaliação Nacional do Rendimento Escolar (Anresc) também conhecida como Prova Brasil, realizada pelos estudantes do $5^{\circ}$ e do $9^{\circ}$ ano? Como Victor seria considerado frente ao Pacto Nacional pela Alfabetização na Idade Certa - PNAIC, instituído pela Portaria No 867, de 4 de julho de 2012, cuja proposta é assegurar que todas as crianças estejam alfabetizadas até os oito anos de idade, ao final do $3^{\circ}$ ano do ensino fundamental? Da mesma forma, a Meta 5 do Plano Nacional de Educação (BRASIL, 2014) prevê "alfabetizar todas as crianças, no máximo, até o final do $3^{\circ}$ (terceiro) ano do ensino fundamental".

Náo se trata de pessimismo nem de descrédito na possibilidade de aprendizagem de toda e qualquer criança. Mas, tensiono essa meta por acreditar que ela desconsidera algumas crianças com acentuada deficiência intelectual, que poderão aprender muitas coisas, mas não a leitura e a escrita. Pelo menos não nos tempos indicados.

Escrevo isso com base em minha atuação com crianças com deficiência, acompanhando a trajetória de algumas desde os primeiros meses de vida, no Programa de Estimulação Essencial, onde muito aprendi. Lembro de João, (nome fictício), com quem trabalhei diretamente dos dois aos oito anos, aproximadamente. João, por alguns anos após seu ingresso no Programa de Estimulação Essencial, não reagia aos estímulos: não apreendia objetos; não apresentava sustentação cefálica; não sorria; não procurava objetos nem olhava para seu interlocutor; aparentava ser surdo e cego e não evidenciava reaçóes intencionais. Inconformada com tantos "nãos" e pressionada por mim mesma a constatar suas aprendizagens, em dias frios, passei gelo em partes de seu corpo. Observei uma discreta reação física em forma de tremor manifestada por João após vários segundos. Nenhuma reação a mais, mesmo que provocadas com distintas tentativas como objetos sonoros e coloridos, movimentos corporais, entre outras. Raramente João chorava, inclusive em casa, segundo a família. Um dia, percebemos que ao chegar na sala de estimulação, João esboçou sons guturais e agitou seu corpo rígido, profundamente marcado pela paralisia cerebral. Na primeira manifestação, fiquei convicta de que ele estava apresentando uma crise convulsiva, o que frequentemente apresentava. Na segunda manifestação, tive a mesma certeza. Porém, a partir da terceira ou quarta reação de João, nas mesmas circunstâncias de chegada na sala, minha "certeza" transformou-se em dúvida e com o passar do tempo, deu lugar à convicção de que João estava comunicando sua satisfação pelo encontro. Minha alegria foi imensa e crescente ao compreender sua mensagem. Suas reaçôes tornaramse mais frequentes e acentuadas, especialmente em relação à música ou passeios no ambiente externo. Registrar as pequenas manifestaçôes de Joâo, por vários anos, foi sempre desafiador e exigiu muita sensibilidade para compreender que naquele corpo marcado pela deficiência existia uma criança, não menos importante do que as que são alfabetizadas na "idade certa" sinalizadas nas políticas nacionais de educação, mas uma "criança diferente". 
Escrevo isso para dizer que assim como João, existem outras crianças com graves comprometimentos e que parecem não estar incluídas no "todas as crianças" citadas na meta 5 do Plano Nacional de Educação. Como serão avaliadas pela escola? Comparadas a si mesmas, como salienta Itard?

Ao fazer referência à avaliação no campo da Educação Especial, Possa; Naujorks e Rios destacam:

O olhar, o exame, a observação, o monitoramento e a experimentação são práticas não discursivas que produzem os discursos de diagnóstico e avaliação, elas têm uma mesma referência, pois têm o poder de estabelecer uma verdade, de inventar uma verdade sobre o sujeito da deficiência e uma forma de atuação do professor da Educação Especial.

Tornando o indivíduo visível, fragilizado e susceptível a uma circunstância, a uma necessidade educacional, social e cultural, produz-se um sujeito pedagógico, com vista a igualá-lo e normalizá-lo. Aquilo que se descreve como necessidade do sujeito é, portanto, um discurso de referência pedagógica, que tem a função de produzir um sujeito que precisa ser educado. (POSSA; NAUJORKS; RIOS, 2012, p. 477).

As autoras nos auxiliam a refletir acerca do contexto escolar que vivemos, com avaliaçóes em larga escala, conduzidas por agentes externos, no qual os professores parecem ser responsabilizados pela aprendizagem dos estudantes. Constatei, por meio de investigaçóes realizadas por mim ou outros pesquisadores, que muitos professores, subjetivados pelas políticas de inclusão, vivem conflitos em relação à avaliação da aprendizagem, possivelmente pelo receio de que recaia sobre eles a suspeita da incompetência. Sem saber como fazer, muitos classificam seus estudantes com deficiência (especialmente a deficiência intelectual) com nota sete, ou seja, o mínimo para aprovar, e, dessa forma, tanto os professores como esses estudantes se tornam invisíveis, sem polemizar a escola e a inclusão.

Pieczkowski (2014) afirma que as políticas de inclusão, disseminadas nos discursos da mídia, nas normativas institucionais, nos apelos à ética e responsabilidade social, funcionam como tecnologias que produzem subjetividades docentes traduzidas, predominantemente, em posturas amorosas. Existe um investimento estratégico que captura o docente e o insere em um jogo de culpa, de sentimento de despreparo para a inclusão. A sensação de fracasso docente também é expressa por Itard, quando escreve ao Ministro do interior da França que o resultado de sua experiência com Victor "oferece bem menos a história dos progressos do aluno do que a dos insucessos do professor" (ITARD, 2000, p. 183).

Atualmente, segundo Pieczkowski (2014), as instituiçôes de educação funcionam como um mecanismo normatizador e normalizador.

Os anormais precisam ser capturados pelo Estado, para terem suas condutas reguladas, controladas e serem computados nos índices de expansão de acesso à educação. A população precisa ser governada para naturalizar a diferença e para conviver com a 
deficiência sem estranhamentos. A discursividade em torno das políticas de inclusão se materializa nas pedagogias que colocam em circulaçáo determinados regimes de verdade amparados no direito à igualdade, aqui entendida como garantia de acesso e permanência para todos, ou à diferença, entendida como a singularidade nos processos de aprendizagem e temporalidades distintas. (PIECZKOWSKI, 2014, p. 111).

Analisando os escritos de Itard ou revisitando minhas memórias relativas à educação de crianças com deficiência, percebo o quanto a Educação Especial requer sensibilidade para valorizar conquistas que podem não aparecer nos currículos definidos previamente ou mesmo nos conteúdos apresentados pela Base Nacional Comum Curricular, tema de intensos debates no cenário da educação atual. Educação Especial, há duzentos anos ou hoje, requer envolvimento, valorização do sujeito, seja ele Victor ou João, e negação de padrôes fixos.

\section{Victor do Aveyron, Hellen Keller, Jõao, Maria e tantas Marias...}

São encontradas na literatura, como nas histórias das meninas e meninos-lobo, a exemplo de Victor do Aveyron na França, de Rômulo e Remo em Roma, de Amala e Kamala na Índia, do menino-urso da Lituânia, subsídios para estudar a constituição da subjetividade humana. Contudo, ainda existem na atualidade, constataçóes de pessoas com deficiência vivendo em isolamento ou restrita interaçáo social, evidenciando a força de concepçôes inatistas de desenvolvimento.

Ao revisitar a história de Victor do Aveyron, lembrei da Maria (nome fictício), uma menina de aproximadamente oito anos quando a conheci. A família, constituída do pai, da mãe e da menina, chegou assustada na APAE onde eu atuava, contexto onde a diferença se mostra intensamente. A família residia em uma região isolada, trabalhava na agricultura e vivia em precárias condiçóes sociais. Maria nunca havia frequentado uma escola. Naquele tempo, na APAE, eu integrava a equipe técnica que realizava a avaliação de ingresso das pessoas com suspeita de deficiência intelectual. Questionei a família por que Maria não ia à escola. O pai respondeu que naquele município não havia escolas para aquele "tipo de criança". Disse-me que não havia nem "posto de saúde" e que o esperado era que antes o "prefeito" fizesse esse investimento, pois não acreditava que investiria em escolas para pessoas que "nunca dariam lucro para a nação".

A mãe, cabisbaixa, não falava. Maria também não falava. Perguntei se Maria oralizava e o pai respondeu que ela falava "um pouco". Cheguei, mais tarde, a duvidar que Maria falasse, pois chegava à escola pelo transporte escolar de seu município de origem e ficava parada na porta. Alguém tinha que conduzi-la à sala de atividades, onde continuava em silêncio.

Naquele primeiro encontro aconteceu algo que muito me marcou: Maria se viu em um espelho, de corpo inteiro, pela primeira vez, afirmaçáo feita pelo pai. Maria interagia com a imagem e encantava-se com as repostas do espelho aos seus movimentos e expressões. 
Perguntei aos pais como era o dia a dia de Maria. O pai respondeu que ela ficava sentada na casa e quando iam à lavoura e o tempo estava bom, ela os acompanhava. Ficava sentada em uma sombra, brincando com gravetos, terra, pedras. Perguntei que brinquedos ela possuía e o pai respondeu que não adiantava dar brinquedos a ela, pois ela os "pinchava3" no chão. Contou que ela só tivera uma boneca.

A história de Maria marcou a minha, especialmente em razão da grande transformação que ela foi apresentando ao longo dos anos. Aprendeu a se comunicar, a dançar, a desenhar, a andar com independência e segurança nos espaços da instituição. Depois de dois ou três anos, ela era outra Maria.

Outro relato histórico acerca da transformação humana propiciada pelo processo de ensino e aprendizagem é o de Helen Keller (1880-1968) e Anne Mansfield Sullivan (1866-1936), escrito por Bennett (1995). Em capítulo dedicado ao que o autor denomina da virtude "amizade", conta sobre Helen Keller, a menina que se tornou surda e cega antes dos dois anos de idade, ficando isolada do mundo. A obra retrata que ela "durante cinco anos viveu selvagem e rebelde, rindo para expressar prazer e chutando, arranhando, emitindo gritos engasgados de surda-muda para expressar o oposto" (BENNETT, 1995, p. 213). O autor relata a mudança na vida da criança desde a chegada da professora Anne Sullivan, também parcialmente cega. Inicialmente, através do toque, e, posteriormente, através do uso do sistema Braille, no espaço de três anos, a professora ensinou Helen a ler e escrever. Aos dezesseis anos, Helen sabia falar suficientemente bem para frequentar a escola e, mais tarde, a universidade. Bennett utiliza as palavras da referida aluna, no registro que segue:

\begin{abstract}
$\mathrm{Na}$ manhã seguinte à sua chegada, minha professora levou-me ao seu quarto e me deu uma boneca. [...]. Enquanto eu brincava com a boneca, Anne Sullivan lentamente escreveu em minha máo a palavra 'b-o-n-e-c-a'. Meu interesse pelo movimento do dedo foi imediato e tentei imitá-lo. Quando enfim consegui fazer as letras corretamente, senti-me inundar de prazer e orgulho infantil. Desci correndo as escadas para mostrar à minha máe, levantei a mão e fiz as letras de boneca. Eu não sabia que estava soletrando uma palavra, nem sabia que existiam palavras. [...]. Nos dias seguintes aprendi a escrever dessa maneira incompreensível uma série de palavras, [...]. Mas minha professora já estava há semanas comigo quando compreendi que tudo tinha um nome. (BENNETT, 1995, p. 214).
\end{abstract}

Tratando-se de crianças com deficiência, e no caso de Helen Keller, com surdez e cegueira, a exclusão social poderá, no dizer de Vygotsky ${ }^{4}$ (1989), determinar deficiências secundárias ${ }^{5}$, limitando a aprendizagem e o desenvolvimento. A história de Helen Keller e Anne Sullivan inspirou o psicólogo russo Vygotsky a afirmar que a interação social tem papel determinante na constituição humana e que a aprendizagem conduz ao desenvolvimento e, portanto, deve ser orientada para os níveis que ainda não foram atingidos, pautando nesse pressuposto o conceito de zona de desenvolvimento proximal. ${ }^{6}$ 
A influência das obras de Vygotsky nas áreas da psicologia e da educação tornam o autor contemporâneo, embora tenha vivido num contexto social, político e científico diferente do nosso. Lev Semionovich Vygotsky nasceu em 17 de novembro de 1896, em Orsha, uma pequena povoação da Bielorússia e faleceu prematuramente, aos 37 anos, em 1934, vítima de tuberculose. A relevância de seu trabalho está no fato de ter contestado, em sua época, as posiçóes de que as funçôes psicológicas superiores ${ }^{7}$, especificamente humanas, poderiam ser desenvolvidas pelos princípios da psicologia animal, em particular os que representam uma combinação mecânica das leis do tipo estímulo-resposta ou resultado unicamente da maturação, esperando a oportunidade de se manifestarem. Para Vygotsky, as funçóes humanas sáo construídas nas relaçôes sociais, e uma criança privada culturalmente pode intensificar suas limitaçóes. Esta afirmação rompe com o determinismo biológico, que causa resignação; ao invés da fatalidade biológica, enfatiza as experiências na construção do sujeito.

Para melhor compreensão dessa ideia, Oliveira (1997) ampara-se em Vygotsky ao afirmar que "[...] é enquanto ser social que o homem cria suas formas de ação no mundo e as relaçôes complexas entre suas várias funçôes psicológicas" (OLIVEIRA, 1997, p. 78). Afirma também que é impossível imaginar o homem privado culturalmente, pois é a vida social que propicia os instrumentos e signos que permitem o desenvolvimento das atividades psicológicas mediadas, tipicamente humanas. $\mathrm{O}$ aprendizado é o processo essencial para a construção do ser humano. A filogênese ${ }^{8}$ e a ontogênese $e^{9}$ têm base no aprendizado e sempre envolvem "[...] a interferência, direta ou indireta, de outros indivíduos e a reconstrução pessoal da experiência e dos significados" (OLIVEIRA, 1997, p. 79).

Contudo, a deficiência frequentemente ainda é vista como uma condição individual, imprimindo aos sujeitos que apresentam tal condição a marca da não aprendizagem. Existe um olhar hegemônico que define a maneira como a escola concebe os sujeitos, buscando as ausências, as diferenças em relação a uma corporeidade e a uma forma de agir consideradas normais. A escola traz as marcas da medicalização, e frequentemente transfere para a área da saúde a autoridade que deve ser da pedagogia: pensar uma escola que valorize as diferenças ao invés de identificá-las e aprisioná-las simbolicamente ou, rotular de estranhos os sujeitos que fogem a um padrão convencionado. A Educação Especial iniciou pela atuação médica, a exemplo do francês Itard e da italiana Maria Montessori (1870-1952) que conheceu, no final do século XIX, os relatórios de Itard.

Para destacar a importância da aprendizagem e do trabalho docente, destaco uma narrativa de Helen Keller apresentada por Bennett:

Anne Sullivan tinha tentado me fazer gravar que 'c-a-n-e-c-a' era caneca e 'á-g-u-a' era água, mas eu continuava confundindo as duas $[\ldots]$.

Andamos até o poço [...]. Alguém estava bombeando água e minha professora colocou minha mão sob a torneira. Enquanto a água jorrava numa das mãos, ela escreveu na outra a palavra água, a princípio devagar, depois rapidamente. [...] Subitamente tive 
uma consciência difusa [...] e de algum modo o mistério da linguagem me foi revelado. Eu sabia que 'á-g-u-a' significava aquela maravilhosa coisa fria que jorrava em minha mão [...].

Deixei o poço ansiosa por aprender. Tudo tinha um nome e cada nome fazia nascer um novo pensamento [...].

Aprendi inúmeras palavras novas naquele dia. [...] seria difícil encontrar uma criança mais feliz que eu quando me deitei, no final daquele dia inesquecível. (BENNETT 1995, p. 214).

A própria Helen Keller narra sua experiência de aprendizagem. Victor, por sua vez, é narrado pelo pesquisador-educador. O que Victor teria dito se pudesse falar sobre si? Por que Victor não falou? Itard perseguiu, em seu trabalho, resposta para a pergunta que o mobilizou, no sentido de compreender "quais seriam o grau de inteligência e a natureza das ideias de um adolescente que, privado, desde sua infância, de qualquer educação, tivesse vivido inteiramente separado dos indivíduos de sua espécie" (ITARD, 2000, p. 133).

Alguns autores suspeitam que Victor fosse um menino autista, o que também pode ser inferido dos escritos de Itard. O autismo, atualmente denominado de Transtorno do Espectro Autista (TEA) ${ }^{10}$, não era conhecido e explicado com essas terminologias no período em que Itard fez a tentativa de educar Victor, pois o quadro foi primeiramente descrito por Léo Kanner, nos Estados Unidos, em 1943. Indago se o fato de Victor não ter sido classificado como autista não foi favorável para que Itard investisse na sua educação.

O modelo médico, amparado em laudos e diagnósticos clínicos, que atribuem a impossibilidades impostas por condiçóes orgânicas, ainda ocupa um lugar hegemônico na Educação Especial. Tais diagnósticos são tomados pela escola como pontos de chegada e justificativa para as não aprendizagens de alguns estudantes. É importante a convicção de que todos aprendem, mas nâo necessariamente as mesmas coisas. $\mathrm{Na}$ proposta da educação inclusiva, o Atendimento Educacional Especializado (AEE) atende às peculiaridades do público da Educação Especial? A inclusão comemorada como estratégia de socialização alterou uma cultura naturalizada da segregação, da separação. Porém, atualmente, é necessário empreender todos os esforços para garantir o direito de aprendizagem de todas as crianças.

\section{Considerações finais}

Os registros de Itard contribuem para a compreensão de uma época, mas provocam, também, a reflexão acerca de indagaçôes ainda presentes: o quanto aspectos biológicos interferem no desenvolvimento? O quanto aspectos sociais interferem nos aspectos biológicos?

As pessoas com deficiência já foram ou ainda são narradas na perspectiva do mito, da monstruosidade, da genética, da endocrinologia, da filantropia, da economia, da legislação, da normalização. Hoje, o foco é o da inclusão. Analisando a forma detalhada e insistente como o professor Itard investe na educação de Victor, na formação de conceitos, fica a indagação do quanto as crianças incluídas em turmas regulares têm contempladas as suas necessidades específicas de aprendizagem. 
A formação docente para atuar com a educação especial ainda é polêmica. Generalista ou especialista? Embora cursos de Licenciatura em educação especial sejam ofertados em algumas universidades do país, não existem Diretrizes Curriculares Nacionais para esse curso. O professor dos anos iniciais, por exemplo, se graduado em Pedagogia, tem acesso durante a graduação a alguns créditos para discutir a educação especial na perspectiva da educação inclusiva (previsto nas Diretrizes Curriculares Nacionais para os Cursos de Licenciatura) e também Libras (previsto no Decreto n. 5.626/2005) de forma abrangente, genérica. Depois, fica a seu critério cursar especialização ou acessar a cursos de capacitação, se forem ofertados, se tiver oportunidade, se tiver disposição para a busca, muitas vezes, de forma individual.

Revisitar a história da educação especial auxilia a refletir sobre problemas atuais, quando a diferença continua sendo negada e a inclusáo pode representar a exclusão de crianças com deficiência. A ambivalência da inclusão se manifesta no fato da escola inclusiva sinalizar para princípios como temporalidade distinta, solidariedade, respeito à diferença, porém organizar-se, predominantemente, com base em princípios da Modernidade sólida, com tempos e espaços fixos para todos.

Independente dos encantos e desencantos de Itard na educação de Victor, da dúvida que persiste se a deficiência do menino foi a causa ou a consequência de seu abandono, a experiência pedagógica analisada com referenciais epistemológicos contemporâneos contribui para a compreensão da necessária ruptura com crenças no determinismo biológico. Fica a convicção da importância da interação social para a aprendizagem e desenvolvimento do sujeito, tenha ele deficiência, ou não.

\section{Referências}

BANKS-LEITE, L.; GALVÃO, I. Uma introdução à história de Victor do Aveyron e suas repercussôes. In: BANKS-LEITE, L.; GALVÃO, I. (Orgs.). A educaçáo de um selvagem: as experiências pedagógicas de Jean Itard. São Paulo: Cortez, 2000. p. 11-24.

BENNETT, J. W. O livro das virtudes. Rio de Janeiro: Nova Fronteira, 1995.

BRASIL. Decreto nº. 5.626, de 22 de dezembro de 2005. Presidência da República. Casa Civil. Regulamenta a Lei no 10.436, de 24 de abril de 2002, que dispóe sobre a Língua Brasileira de Sinais - LIBRAS, e o art. 18 da Lei no 10.098, de 19 de dezembro de 2000. Diário Oficial [da] República Federativa do Brasil, Brasília, DF, 23 dez. 2005. Disponível em: <http://www.planalto.gov.br/ccivil_03/_ato2004-2006/2005/decreto/d5626. htm>. Acesso em: 10 fev. 2008.

Ministério da Educação. Portaria no 867, de 4 de julho de 2012. Institui o Pacto Nacional pela Alfabetizaçấo na Idade Certa e as açóes do Pacto e define suas diretrizes gerais. Diário Oficial [da] República Federativa do Brasil. Brasília, DF, 5 jul. 2012, seçâo I, p. 23. Disponível em: <http://download.inep.gov.br/ educacao_basica/provinha_brasil/legislacao/2013/portaria_n867_4julho2012_provinha_brasil.pdf>. Acesso em: 07 nov. 2015 .

Presidência da República. Casa Civil. Subchefia para Assuntos Jurídicos. Lei no 12.764, de 27 de dezembro de 2012. Institui a Política Nacional de Proteçáo dos Direitos da Pessoa com Transtorno do Espectro Autista; e altera o $\$ 3$ o do art. 98 da Lei no 8.112, de 11 de dezembro de 1990. Diário Oficial [da] República Federativa do Brasil, Brasília, DF, 28 dez. 2012b, seção I, p. 2.

Presidência da República. Casa Civil. Lei no 13.005 de 25 de junho de 2014. Aprova o Plano Nacional de Educação - PNE e dá outras providências. Diário Oficial [da] República Federativa do Brasil, Brasília, DF, 26 jun. 2014b. Disponível em: <http://fne.mec.gov.br/images/doc/pne-2014-20241.pdf>. Acesso em: 20 jul. 2014.

CASTORINA, J. A. O debate Piaget-Vygotsky: a busca de um critério para sua avaliação. São Paulo: Ática, 1998. 
GALVÃO, I.; DANTAS, H. O lugar das interaçôes sociais e das emoçôes na experiência de Jean Itard com Victor do Aveyron. In: BANKS-LEITE, L.; GALVÃO, I. (Orgs.). A educaçáo de um selvagem: as experiências pedagógicas de Jean Itard. São Paulo: Cortez, 2000. p. 83-103.

ITARD, J. Relatório I - Da educação de um homem selvagem ou dos primeiros desenvolvimentos físicos e morais do jovem selvagem do Aveyron. In: BANKS-LEITE, L.; GALVÃO, I. (Orgs.). A educaçáo de um selvagem: as experiências pedagógicas de Jean Itard. São Paulo: Cortez, 2000. p. 123-177.

Relatório II - Relatório feito a Sua Excelência o Ministro do Interior sobre os novos desenvolvimentos e o estado atual do Selvagem do Aveyron. In: BANKS-LEITE, L.; GALVÃO, I. (Orgs.). A educaçáo de um selvagem: as experiências pedagógicas de Jean Itard. São Paulo: Cortez, 2000. p. 179-229.

OLIVEIRA, M. K. Vygotsky: Aprendizado e desenvolvimento: um processo sócio-histórico. São Paulo: Scipione, 1997.

PESSOTI, I. Deficiência mental: da superstição à ciência. São Paulo: Queirós/Edusp, 1984.

PIECZKOWSKI, T. M. Z. Inclusáo de estudantes com deficiência na educaçáo superior: efeitos na docência universitária. 2014. 208f. Tese (Doutorado em Educaçấo) - Universidade Federal de Santa Maria, Santa Maria, 2014.

POSSA, L. B.; NAUJORKS, M. I.; RIOS, G. M. S. Matizes do discurso sobre avaliação na formação de professores da Educação Especial. Revista Educaçáo Especial, Santa Maria: UFSM, v. 25, n. 44, p. 465-489, set./ dez. 2012.

VYGOTSKY, L. S. Fundamentos da defectologia: obras completas. Ciudad de La Habana: Pueblo y Educación, 1989. T. V.

A formaçáo social da mente. 6. ed., São Paulo: Martins Fontes, 1999.

\section{Notas}

${ }^{1} \mathrm{O}$ termo excepcionais era adotado na década de 1950 a 1960 , período em que foram fundadas as primeiras APAEs no Brasil.

${ }^{2}$ Termo adotado na época para designar pessoas surdas.

${ }^{3}$ Pinchar, expressão usada na regiáo, significa jogar, atirar.

${ }^{4} \mathrm{O}$ nome Vygotsky, é encontrado escrito de várias formas na bibliografia existente, escrito de várias formas: Vygotsky, Vigotski, Vygotski, Vigotskji, Vigotskii, Vigotsky. Optei por empregar a grafia Vygotsky, adotada, segundo Castorina (1998) por publicaçóes brasileiras (com exceçăo da coletânea Linguagem, desenvolvimento e aprendizagem, na qual grafou-se Vigotskii). Preservarei, nas indicaçôes bibliográficas, a ortografia adotada em cada uma delas.

${ }^{5}$ Vygotsky (1989) menciona deficiência primária (biológica) e secundária (agravamento da deficiência primária devido à privaçâo social).

${ }^{6}$ Conceituada pelo autor como "a distância entre o nível de desenvolvimento real, que se costuma determinar através da soluçăo independente de problemas, e o nível de desenvolvimento potencial, determinado através da soluçáo de problemas sob a orientação de um adulto ou em colaboraçăo com companheiros mais capazes" (VIGOTSKI, 1999, p. 112).

${ }^{7}$ Processos psicológicos superiores são aqueles que caracterizam o funcionamento psicológico tipicamente humano: açôes conscientemente controladas, atenção voluntária, memorizaçáo ativa, pensamento abstrato, comportamento intencional. (OLIVEIRA, 1997, p. 23).

${ }^{8}$ Refere-se à evolução de uma espécie.

${ }^{9}$ Refere-se ao desenvolvimento de um indivíduo.

${ }^{10}$ Terminologia adotada pela Lei no 12.764 , de 27 de dezembro de 2012. 


\section{Correspondência}

Tania Mara Zancanaro Pieczkowski - Universidade Comunitária da Regiáo de Chapecó. Avenida Senador Atílio Fontana, 591 E, Efapi, CEP: 89809-000, caixa-postal: 747 - Chapecó, Santa Catarina - Brasil.

E-mail: taniazp@unochapeco.edu.br

Recebido em 03 de junho de 2016

Aprovado em 23 de agosto de 2016 